\title{
Correction to: A pH-responsive genetic sensor for the dynamic regulation of D-xylonic acid accumulation in Escherichia coli
}

\author{
Angelo B. Bañares ${ }^{1} \cdot$ Kris Niño G. Valdehuesa ${ }^{1} \cdot$ Kristine Rose M. Ramos $^{1} \cdot$ \\ Grace M. Nisola ${ }^{1} \cdot$ Won-Keun Lee ${ }^{2} \cdot$ Wook-Jin Chung ${ }^{1}$
}

Published online: 16 January 2020

(C) Springer-Verlag GmbH Germany, part of Springer Nature 2020

\section{Correction to: Applied Microbiology and Biotechnology https://doi.org/10.1007/s00253-019-10297-0}

In the published version, the $y$-axis data of Fig. $3 \mathrm{c}$ was incorrectly inserted (OD600 instead of D-xylonate ( $\mathrm{g}$ $\mathrm{L}^{-1}$ ) and the $\mathrm{x}$-axes of Figs. 3b, 3d, 3e and $3 \mathrm{f}$ ended at $48 \mathrm{~h}$ instead of $72 \mathrm{~h}$.

The online version of the original article can be found at https://doi.org/ $10.1007 / \mathrm{s} 00253-019-10297-0$

Won-Keun Lee

wklee@mju.ac.kr

Wook-Jin Chung

wjc0828@gmail.com

1 Department of Energy Science and Technology (DEST), Energy and Environment Fusion Technology Center (E2FTC), Myongji

University, Myongji-ro 116, Cheoin-gu,

Yongin 17058, Gyeonggi-do, Republic of Korea

2 Division of Bioscience and Bioinformatics, Myongji University, Myongji-ro 116, Cheoin-gu, Yongin 17058, Gyeonggi-do, Republic of Korea 
See the correct Fig. 3 below.

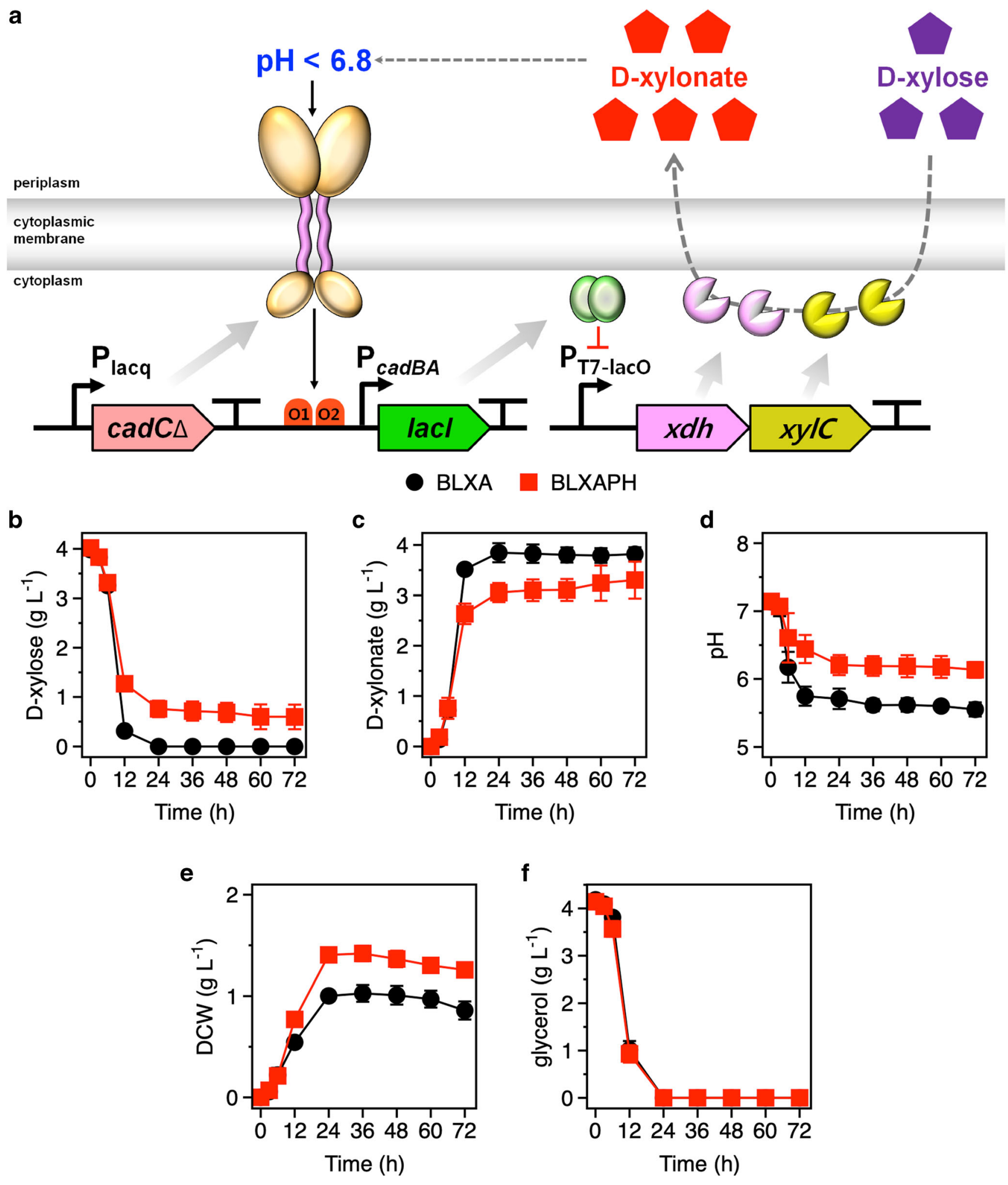

